This is a pre-print version

Please note that there are difference exist between

the published article. 


\section{Substrate-like water soluble lipase inhibitors from}

\section{Filipendula kamtschatica}

Eisuke Kato ${ }^{a}$, Michitsugu Yama ${ }^{a}$, Ryo Nakagomi ${ }^{a}$, Toshiro Shibata ${ }^{b}$, Keizo Hosokawa ${ }^{c}$, Jun Kawabata $^{\mathrm{a}, *}$

${ }^{a}$ Laboratory of Food Biochemistry, Division of Applied Bioscience, Graduate School of Agriculture, Hokkaido University, Kita-ku, Sapporo, Hokkaido 060-8589, Japan

${ }^{b}$ Hokkaido Division, Research Center for Medicinal Plant Resources, National Institute of Biomedical Innovation, Nayoro 096-0065, Japan

${ }^{\mathrm{c}}$ Department of Nutritional Management, Faculty of Health Sciences, Hyogo University, Kakogawa 675-0195, Japan

\section{Corresponding Author}

*Tel/Fax +81-11-706-2496, E-mail junk@chem.agr.hokudai.ac.jp 


\begin{abstract}
Filipendula kamtschatica is a plant utilized as a traditional medicine by Ainu people in Japan, but its chemical constituents are not much studied. Pancreatic lipase inhibitors are a promising tool for the treatment of obesity. We searched for natural lipase inhibitors from F. kamtschatica and two new compounds were isolated along with the known flavonoid glycoside. The structure elucidation of new compounds revealed these two to be 2-O-caffeoyl-4-O-galloyl-L-threonic acid and 3-O-caffeoyl-4-O-galloyl-L-threonic acid, which can be recognized as a pancreatic lipase’s substrate-like structure. The isolated compounds all showed an inhibitory activity against porcine pancreatic lipase and one of the isomer, 3-O-caffeoyl-4-O-galloyl-L-threonic acid, possessed the most potent activity with $\mathrm{IC}_{50}$ value showing an order lower value compared to others. The substrate-like structure of the new compounds seemed to be important for their activity.
\end{abstract}

Keywords: Filipendula kamtschatica; pancreatic lipase inhibitor; obesity; traditional medicine 
Obesity is a condition caused by excess energy intake leading to fat accumulation in adipocytes. A major problem of obesity is that it can eventually cause diseases like diabetes mellitus, hypertension, hyperlipidemia, and arteriosclerosis. ${ }^{1}$ The number of obesity patients is increasing, and obesity is becoming a major health problem around the world. ${ }^{2}$

One reason for increased obesity in patients is excess fat taken in during a meal. Fats, typically triacylglycerol, form a micelle with the aid of pancreatic juices in the gastrointestinal tract. The micellar solution of triacylglycerol is then hydrolyzed by pancreatic lipase. The released monoacylglycerol and fatty acids are then absorbed from the intestine.

In the above mechanism, pancreatic lipase is a primary agent responsible for the absorption of lipids. Several pancreatic lipase inhibitors, like Orlistat and Cetilistat, are clinically used or are currently in a trial for use as an anti-obesity drug. ${ }^{1,3,4}$ In addition, natural lipase inhibitors are actively studied as potential drug candidates or for use as food additives. ${ }^{5}$

During the search for natural lipase inhibitors among Japanese traditional medicinal plants, we found Filipendula kamtschatica as a candidate plant. ${ }^{6}$ F. kamtschatica is a perennial plant that belongs to the Rosaceae family. The plant is distributed from the northern area of Japan through the Kuril Islands to the Kamchatka peninsula. The infusion of the plant is known for being used to wash eczema and hives and as an antidiarrheal agent by the Ainu people. Medicinal usage against obesity is not known, but only a few chemical studies are reported for this plant, making it an attractive target in the search for new lipase inhibitors. ${ }^{7,8}$

A dried aerial part of F. kamtschatica (150 g) was extracted twice with 50\% aq. MeOH to afford $37.9 \mathrm{~g}$ of crude extract showing 95\% inhibition at $2.5 \mathrm{mg} / \mathrm{mL}$. The crude extract was partitioned between water and ethyl acetate to afford the water layer (33.7 g, 90\% inhibition at 
$2.8 \mathrm{mg} / \mathrm{mL}$ ). The water layer was then subjected to chromatographic purification using activityguided fractionation. Column chromatography of the water layer over Diaion HP-20, ODS, and preparative HPLC yielded compounds 1 (220 mg), 2 (110 mg), and 3 (54 mg).

The molecular formula of $\mathbf{1}$ was determined to be $\mathrm{C}_{26} \mathrm{H}_{28} \mathrm{O}_{16}$ using HR-ESI-MS (found $\mathrm{m} / \mathrm{z}$ 595.1318 [M-H]', calcd. for $\mathrm{C}_{26} \mathrm{H}_{27} \mathrm{O}_{16}$ 595.1300). Analysis of the ${ }^{1} \mathrm{H}$ NMR spectroscopic data indicated $\mathbf{1}$ to be a flavonoid with two hexoses. Further analysis of the compound revealed $\mathbf{1}$ to be quercetin 3-O- $\beta$-xylopyranosyl-( $1 \rightarrow 2)-O-\beta$-galactopyranoside, which was confirmed by comparing the NMR spectroscopic data with the reported data. ${ }^{9}$

The HR-ESI-MS analysis of 2 (found $m / z 473.0672[\mathrm{M}+\mathrm{Na}]^{+}$, calcd. for $\mathrm{C}_{20} \mathrm{H}_{18} \mathrm{O}_{12} \mathrm{Na}$ 473.0696) suggested the molecular formula to be $\mathrm{C}_{20} \mathrm{H}_{18} \mathrm{O}_{12}$. Analysis of the ${ }^{1} \mathrm{H} /{ }^{13} \mathrm{C} N M R$ spectroscopic data of $\mathbf{2}$ indicated the presence of caffeic acid and gallic acid as components of the structure. The remaining moiety, with a molecular formula of $\mathrm{C}_{4} \mathrm{H}_{8} \mathrm{O}_{5}$, was predicted to be 2,3,4-trihydroxybutanoic acid. Solvolysis of $\mathbf{2}$ in methanol under acidic conditions gave four products. Two of them were determined to be methyl caffeate and methyl gallate. The other two compounds were confirmed to be the methyl ester and lactonized product of 2,3,4trihydroxybutanoic acid from ${ }^{1} \mathrm{H}$ NMR spectroscopic data, and was predicted as either the derivatives of threonic acid or erythronic acid. The ${ }^{1} \mathrm{H}$ NMR spectroscopic data and optical rotation were compared with the synthetic methyl L-threonate, which was derived from the commercial calcium L-threonate. ${ }^{1} \mathrm{H}$ NMR showed identical spectrum between the solvolysis product and the synthetic methyl L-threonate (see supplementary data), optical rotation of the two showed reasonable value (solvolysis product of $2:[\alpha]_{D}{ }^{28}+6.5^{\circ}\left(c=0.5\right.$, MeOH), synthetic: $[\alpha]_{D}{ }^{28}$ $\left.+6.6^{\circ}(c=0.5, \mathrm{MeOH})\right)$ and the remaining moiety was determine as L-threonic acid. The ester bonds between L-threonic acid, caffeic acid, and gallic acid were determined by the HMBC 
spectrum. Correlations from H-2 $(\delta=5.08)$ to C-9' $(\delta=166.0)$, and H-4 $(\delta=4.18)$ to C-7' ' $(\delta=$ 165.5) were seen, and the structure of $\mathbf{2}$ was determined to be 2-O-caffeoyl-4-O-galloyl-Lthreonic acid (Table 1).

The HR-ESI-MS analysis of $\mathbf{3}$ (found $\mathrm{m} / \mathrm{z} 473.0672[\mathrm{M}+\mathrm{Na}]^{+}$, calcd. for $\mathrm{C}_{20} \mathrm{H}_{18} \mathrm{O}_{12} \mathrm{Na}$ 473.0696) showed the same value with 2 , and molecular formula was determined to be $\mathrm{C}_{20} \mathrm{H}_{18} \mathrm{O}_{12}$. Analysis of the ${ }^{1} \mathrm{H}$ NMR spectroscopic data and solvolysis of $\mathbf{3}$ revealed this compound to be constructed from the same structural components as $\mathbf{2}$ and is in fact an isomer of 2. HMBC spectroscopic analysis of 3 showed the presence of correlations from $\mathrm{H}-3(\delta=5.50)$ to C-9' $(\delta=165.6)$, and H-4 ( $\delta=4.30$ and 4.44$)$ to C-7' ' $(\delta=165.6)$; however, the two carbonyl carbons were detected at the same chemical shift preventing the determination of its structure. Further analysis of $\mathbf{3}$ using HPLC and NMR revealed slowly the apparent isomerization of $\mathbf{3}$ to $\mathbf{2}$ in a solution. ${ }^{10}$ Thus, the structure of $\mathbf{3}$ was determined to be 3-O-caffeoyl-4-O-galloyl-Lthreonic acid (Table 1).

The lipase inhibitory activity of isolated compounds was tested against the porcine pancreatic lipase (PPL) with micellar solution of triolein as a substrate (Table 2). ${ }^{11}$ Flavonoid glycoside $\mathbf{1}$ showed moderate inhibitory activity against PPL. Several flavonoids are reported as lipase inhibitors. ${ }^{12-15}$ The $\mathrm{IC}_{50}$ value of these reported flavonoids varies in a wide range from an order below $\mu \mathrm{M}$ to an order above $\mathrm{mM}$. Their direct comparison is difficult since several different substrates were used in the experiments to determine their inhibitory activity. However, these flavonoids, with or without glycosides, seem to be a moderate inhibitor of PPL.

Among the two regio-isomers, $\mathbf{2}$ also showed moderate inhibition. However, $\mathbf{3}$ possessed an order higher lipase inhibitory activity with $\mathrm{IC}_{50}$ value at low $\mu \mathrm{M}$ range. Numbers of plant derived 
natural lipase inhibitors with activity at this range or even lower are reported. ${ }^{12,14-17}$ These reports employ soluble substrates ( $p$-nitrophenylbutyrate) or a monomeric substrate (4methylumbelliferyl oleate). The assay method with these substrates are commonly employed due to their ease in use, but the method tend to show three to four order, or even more, higher activity compared to the relatively natural like method which employs micellar solution of triolein as a substrate. ${ }^{18,19}$ Concerning the use of triolein in this report, 3 belongs to the group of natural compounds with high lipase inhibitory activity.

Several lipase inhibitors are known which has structure resembling to diacylglycerol, the substrate of pancreatic lipase. ${ }^{20,21}$ In the structures of $\mathbf{2}$ and 3, no long chain hydrocarbons are present, but L-threonic acid and the two esters are recognizable as a model of diacylglycerol. To see if this diacylglycerol-like structure is influencing the activity of $\mathbf{2}$ and 3, each liberated moieties, gallic acid, caffeic acid and L-threonic acid were tested for their lipase inhibitory activity (Table 2). These three partial structures all showed $\mathrm{IC}_{50}>1 \mathrm{mM}$ against PPL, ${ }^{22}$ and the diacylglycerol-like structure was shown to be important for the inhibitory activity of $\mathbf{2}$ and $\mathbf{3}$. Difference in the inhibitory activity between $\mathbf{2}$ and $\mathbf{3}$ is uncertain at this moment, but the ester bond position must be the key point.

In conclusion, phenolcarboxylic acids esters of L-threonic acid (2, 3) were isolated together with the known flavonoid glycoside (1) from F. kamtschatica. Isolation of a similar compound, 2-O-galloyl-4-O-caffeoyl-L-threonic acid has been previously reported, ${ }^{23}$ but this is the first study to report the isolation and lipase inhibitory activity of $\mathbf{2}$ and $\mathbf{3}$. Compounds $\mathbf{2}$ and $\mathbf{3}$ were regio-isomers of caffeic acid ester, but $\mathbf{3}$ showed an order higher activity compared to 2 . Many of the synthetic or natural lipase inhibitors appear in lipophilic form (ex. Orlistat, ${ }^{1}$ Cetilistat, ${ }^{3}$ di-/triterpenes, ${ }^{16,24,25}$ and long chain hydrocarbons. ${ }^{26}$ ). Although the inhibitory activity was weaker 
than the current utilized drug Orlistat, compound $\mathbf{3}$ is water soluble and also belongs to a group with highest activity among the plant derived natural lipase inhibitors. Further study of this unique diacylglycerol like lipase inhibitor is currently ongoing, which may lead to the development of a new class of water-soluble potent lipase inhibitors.

\section{Acknowledgement}

We thank Instrumental Analysis Division, Equipment Management Center, Creative Research Institution, Hokkaido University for measuring the mass spectra.

\section{Supplementary data}

Detailed experimental procedures and NMR spectra of 1-3 and methyl L-threonate;

Supplementary data associated with this article can be found, in the online version

\section{References and notes}

1. Henness, S.; Perry, C. M. Drugs 2006, 66, 1625.

2. $\quad$ World Health Organization (WHO). Fact sheet No. 311, "Obesity and overweight", http://www.who.int/mediacentre/factsheets/fs311/en/index.html, accessed June 2012.

3. Kopelman, P.; de H. Groot, G.; Rissanen, A.; Rossner, S.; Toubro, S.; Palmer, R.; Hallam, R.; Bryson, A.; Hickling, R. I. Obesity 2010, 18, 108.

4. $\quad$ Filippatos, T. D.; Derdemezis, C. S.; Gazi, I. F.; Nakou, E. S.; Mikhailidis, D. P.; Elisaf, M. S. Drug Safety 2008, 31, 53.

$5 . \quad$ de la Garza, A. L.; Milagro, F. I.; Boque, N.; Campion, J.; Martinez, J. A. Planta Med. 2011, 77, 773.

6. 139 medicinal plants belonging to Hokkaido, Japan were screened and F. kamtschatica was found as one of the highest lipase inhibiting plants.

7. Hashimoto, Y.; Kawanishi, K.; Tomita, H.; Moriyasu, M.; Uhara, Y.; Kato, A. Anal. Lett. 1983, 16, 317.

8. Kanetoshi, A.; Inoue, S.; Anetai, M.; Fujimoto, T.; Aoyagi, M.; Sato, M. Rep. Hokkaido Inst. Pub. Health 2005, 55, 49.

9. Jong-Anurakkun, N.; Bhandari, M. R.; Kawabata, J. Food Chem. 2007, 103, 1319.

10. Isomerization was not seen when dried and stored as a solid.

11. Han, L. K.; Takaku, T.; Li, J.; Kimura, Y.; Okuda, H. Int. J. Obes. Relat. Metab. Disord. 1999, 23, 98. 
12. Lee, E. M.; Lee, S. S.; Chung, B. Y.; Cho, J. Y.; Lee, I. C.; Ahn, S. R.; Jang, S. J.; Kim, T. H. Molecules 2010, 15, 8251.

13. Shin, J. E.; Han, N. J.; Kim, D. H. Biol. Pharm. Bull. 2003, $26,854$.

14. Nakai, M.; Fukui, Y.; Asami, S.; Toyoda-Ono, Y.; Iwashita, T.; Shibata, H.; Mitsunaga,

T.; Hashimoto, F.; Kiso, Y. J. Agric. Food Chem. 2005, 53, 4593.

15. Ahn, J. H.; Liu, Q.; Lee, C.; Ahn, M.-J.; Yoo, H.-S.; Hwang, B. Y.; Lee, M. K. Bioorg. Med. Chem. Lett. 2012, 22, 2760.

16. Ninomiya, K.; Matsuda, H.; Shimoda, H.; Norihisa, N.; Kasajima, N.; Yoshino, T.; Morikawa, T.; Yoshikawa, M. Bioorg. Med. Chem. Lett. 2004, 14, 1943.

17. Liu, D.-Z.; Wang, F.; Liao, T.-G.; Tang, J.-G.; Steglich, W.; Zhu, H.-J.; Liu, J.-K. Org. Lett. 2006, 8, 5749.

18. Kusano, R.; Andou, H.; Fujieda, M.; Tanaka, T.; Matsuo, Y.; Kouno, I. Chem. Pharm. Bull. 2008, 56, 266.

19. Ikeda, I.; Tsuda, K.; Suzuki, Y.; Kobayashi, M.; Unno, T.; Tomoyori, H.; Goto, H.; Kawata, Y.; Imaizumi, K.; Nozawa, A.; Kakuda, T. J. Nutr. 2005, 135, 155.

20. Han, L. K.; Li, D. X.; Xiang, L.; Gong, X. J.; Kondo, Y.; Suzuki, I.; Okuda, H. Yakugaku Zasshi. 2006, 126, 43.

21. Watanabe, D.; Kerakawati, R.; Morita, T.; Nakamura, T.; Ueno, K.; Kumamoto, T.; Nakanishi, W.; Ishikawa, T.; Uzawa, J.; Seki, H.; Tachi, M.; Harada, K.-i.; Higuchi, Y.; Chaichantipyuth, C. Heterocycles 2009, 78, 1497.

22. Inhibitory activity at $1 \mathrm{mM}$ : gallic acid $4 \%$, caffeic acid $13 \%$, L-threonic acid $30 \%$.

23. Lee, D.; Kang, S. J.; Lee, S. H.; Ro, J.; Lee, K.; Kinghorn, A. D. Phytochemistry 2000, 53, 405.

24. Jang, D.; Lee, G.; Kim, J.; Lee, Y.; Kim, J.; Kim, Y.; Kim, J. Arch. Pharmacal. Res. 2008, 31, 666.

25. Morikawa, T.; Li, X.; Nishida, E.; Nakamura, S.; Ninomiya, K.; Matsuda, H.; Oda, Y.; Muraoka, O.; Yoshikawa, M. Helv. Chim. Acta 2010, 93, 573.

26. Chiou, A.; Markidis, T.; Constantinou-Kokotou, V.; Verger, R.; Kokotos, G. Org. Lett. 2000, 2, 347. 
Structures and Tables
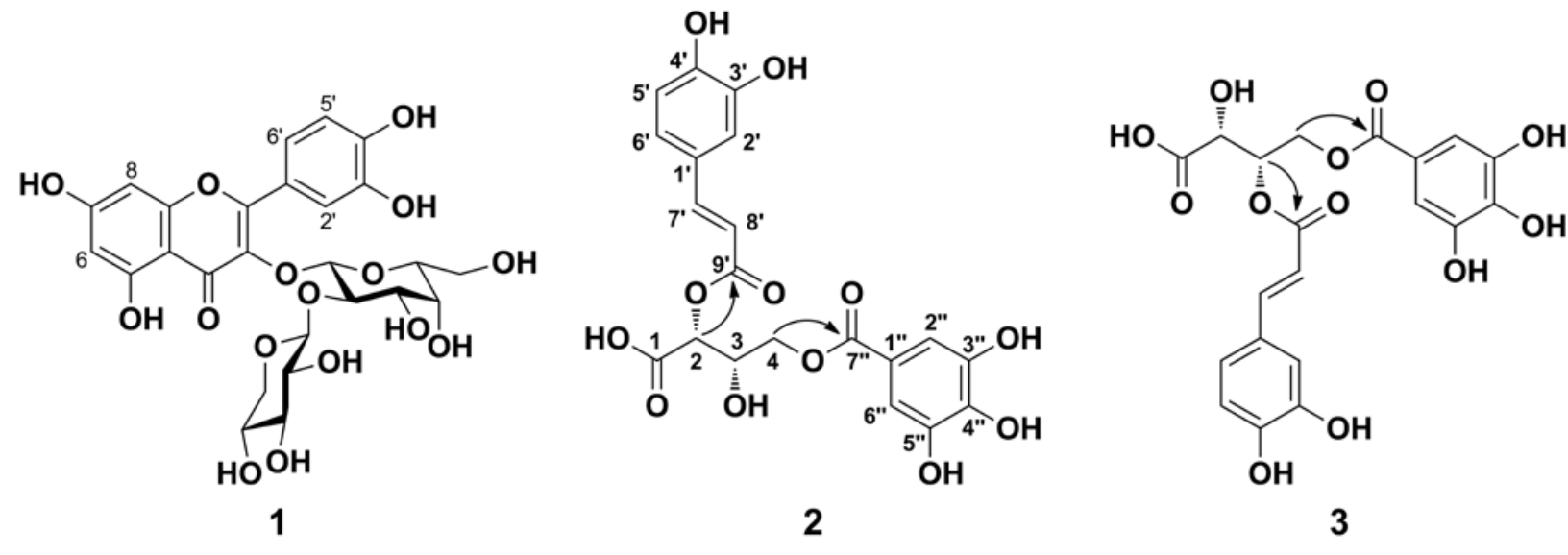

: HMBC correlation

Table 1. ${ }^{1} \mathrm{H}\left(500 \mathrm{MHz}\right.$, rt) and ${ }^{13} \mathrm{C}(125 \mathrm{MHz}$, rt) NMR spectroscopic data of 2 and 3 in DMSO- $d_{6}(\mathrm{~J}$ in $\mathrm{Hz})$

\begin{tabular}{|c|c|c|c|c|}
\hline \multirow[b]{2}{*}{ No. } & \multicolumn{2}{|l|}{2} & \multirow[t]{2}{*}{3} & \multirow[b]{2}{*}{$\delta_{\mathrm{C}}$} \\
\hline & $\delta_{\mathrm{H}}$ & $\delta_{\mathrm{C}}$ & & \\
\hline 1 & & 169.5 & & 172.7 \\
\hline 2 & $5.08(\mathrm{~d}, 2.5)$ & 72.5 & 4.24 (br s) & 71.4 \\
\hline 3 & 4.31 (ddd, 2.5, 6.3, 6.7) & 68.0 & $5.50(\mathrm{~m})$ & 69.5 \\
\hline 4 & $4.16(\mathrm{dd}, 6.7,10.9)$ & 64.1 & 4.30 (dd, 11.2, 7.7) & 62.7 \\
\hline & $4.20(\mathrm{dd}, 6.3,10.9)$ & & $4.44(\mathrm{dd}, 11.2,4.7)$ & \\
\hline 1 ' & & 125.4 & & 125.4 \\
\hline $2^{\prime}$ & $7.05(d, 1.6)$ & 114.9 & $7.01(\mathrm{~d}, 1.4)$ & 115.1 \\
\hline $3^{\prime}$ & & 145.6 & & 146.0 \\
\hline $4^{\prime}$ & & 148.6 & & 148.5 \\
\hline 5 ' & $6.77(\mathrm{~d}, 8.2)$ & 115.8 & $6.75(\mathrm{~d}, 8.3)$ & 116.0 \\
\hline $6^{\prime}$ & 7.01 (dd, 8.2, 1.6) & 121.6 & $6.97(\mathrm{dd}, 8.3,1.4)$ & 121.6 \\
\hline $7^{\prime}$ & $7.58(\mathrm{~d}, 16.0)$ & 146.2 & $7.48(\mathrm{~d}, 15.9)$ & 145.7 \\
\hline 8' & $6.30(\mathrm{~d}, 16.0)$ & 113.2 & $6.16(\mathrm{~d}, 15.9)$ & 113.5 \\
\hline 9 ' & & 166.0 & & 165.6 \\
\hline 1 , & & 119.0 & & 119.2 \\
\hline $2^{\prime}$, & $6.94(\mathrm{~s})$ & 108.7 & $6.90(\mathrm{~s})$ & 108.7 \\
\hline 3', & & 145.6 & & 145.7 \\
\hline 4', & & 138.6 & & 138.9 \\
\hline 5, & & 145.6 & & 145.7 \\
\hline 6, & $6.94(\mathrm{~s})$ & 108.7 & $6.90(\mathrm{~s})$ & 108.7 \\
\hline $7^{\prime \prime}$ & & 165.5 & & 165.6 \\
\hline
\end{tabular}


Table 2. Pancreatic lipase inhibitory activity of tested compounds.

\begin{tabular}{ll}
\hline Compound & $\mathrm{IC}_{50}(\mu \mathrm{M})$ \\
\hline $\mathbf{1}$ & 300 \\
$\mathbf{2}$ & 246 \\
$\mathbf{3}$ & 26 \\
Caffeic acid & $>1000$ \\
Gallic acid & $>1000$ \\
L-threonic acid & $>1000$ \\
Orlistat (reference) & 0.22 \\
\hline
\end{tabular}

